\title{
Energy metabolism and performance of Mytilus galloprovincialis under anaerobiosis
}

\author{
Jose M.F. Babarro*, Uxío Labarta and María José Fernández Reiriz \\ Instituto de Investigaciones Marinas CSIC, Eduardo Cabello 6, 36208 Vigo, Spain. \\ *Corresponding author, e-mail: jbabarro@iim.csic.es
}

\begin{abstract}
Intertidal individuals of Mytilus galloprovincialis were exposed to anaerobiosis in laboratory at $22^{\circ} \mathrm{C}$ and a set of biochemical metabolites and survival potential determined. Differences in survival potential between individuals emersed or kept in oxygen-free seawater were residual according to $\mathrm{ST}_{50}$ values (survival time, $P \approx 0.05$ ) but emersed individuals survived significantly longer when considering $\mathrm{ST}_{90-100}$ values $(P<0.05)$. Anaerobiosis was similarly activated under both emersion and incubation in anoxic seawater after $6 \mathrm{~h}$ according to a sevenfold increase in succinate. Longer exposure of individuals (up to $48 \mathrm{~h}$ ) caused succinate (and propionate) to increase but in a higher magnitude under incubation with anoxic seawater. Propionate appeared in soft tissues after $24 \mathrm{~h}$ of incubation in anoxic seawater and after $48 \mathrm{~h}$ when individuals were emersed. Glycogen was not utilized after $6 \mathrm{~h}$ in any case, but was progressively used with longer exposure times and in a higher magnitude under incubation in anoxic seawater $(48 \mathrm{~h}$ ). Adenylate energy charge (AEC) was highly affected by both exposure time $(P<0.001)$ and anaerobic treatment $(P<0.01)$. Rapid breakdown of ATP and phospho-Larginine (PLA) did occur during the first $24 \mathrm{~h}$ of anaerobiosis, the latter ATP drop was accompanied by slight increase of ADP but strong increase of AMP that accumulated in a higher magnitude under incubation in anoxic seawater. Biochemical results of the present study suggested a certain degree of aerobiosis for emersed M. galloprovincialis that in turn is linked to a slight but significant longer survival performance. Most significant biochemical changes occurred during the first $24 \mathrm{~h}$ of oxygen deprivation, but significant differences between treatments were observed after 24-48 h. These lag differences in biochemical metabolites together with more accurate survival analyses have to be considered when investigating the energy metabolism linked to the anaerobic performance of $M$. galloprovincialis.
\end{abstract}

\section{INTRODUCTION}

The littoral zone represents a highly variable environment that significantly affects the metabolism of marine molluscs because of the incidence of cyclic exposure to air and consequently, intermittent hypoxia/anoxia that caused important changes in the energy metabolism of animals. Survival in air has been suggested as a useful tool to reflect even finer differences than other parameters such as condition factor, feeding rate and glycogen content (Thomas et al., 1999). A link between anaerobic performances as survival capacity and biochemical data has been demonstrated between Venus gallina and Scapharca inaequivalvis (Brooks et al., 1991) and for individuals of Littorina saxatilis (Sokolova et al., 2000). A large body of data is available on mussels' mortality in air, anaerobic end product accumulation, anaerobic depletion of glycogen, adenylates and phosphagens (Eertman et al., 1993; Isani et al., 1995; Sukhotin \& Pörtner, 1999 among many others) but less attention has been focused on the anaerobic performance of individuals with regard to biochemical analyses for the specific case of Mytilus galloprovincialis. A certain degree of aerial respiration and the potential to perform metabolic arrest by inducing metabolic suppression (energy conservation) are the most important strategies that individuals carry out to cope with oxygen deprivation in the littoral zone (Widdows et al., 1979; Hochachka, 1985; Shick et al., 1988; Storey et al., 1990). The capacity of aerial respiration for the specific case of M. edulis and M. galloprovincialis have been reported to represent $6-17 \%$ of aquatic rates (Widdows et al., 1979). The aim of this study was to investigate a number of biochemical changes that the mussel Mytilus galloprovincialis activates under environmental restrictions represented by air exposure (emersion) at $22^{\circ} \mathrm{C}$ and compared to lack of oxygen in the seawater. A comparison between biochemical data and the eventual performances in terms of survival will be discussed.

\section{MATERIALS AND METHODS} Sampling of individuals

Mytilus galloprovincialis was collected at an intertidal location exposed to active wave action in the outer area of Ría de Vigo (north-western Spain) in summer. Daily average emersion time in the field was around $30 \%$ and, seawater and air temperature were $15^{\circ} \mathrm{C}\left(14-16^{\circ} \mathrm{C}\right.$ summer average values) and $15-28^{\circ} \mathrm{C}$ taking into account the daily cycle of tidal exposure, respectively. Mean values of shell 


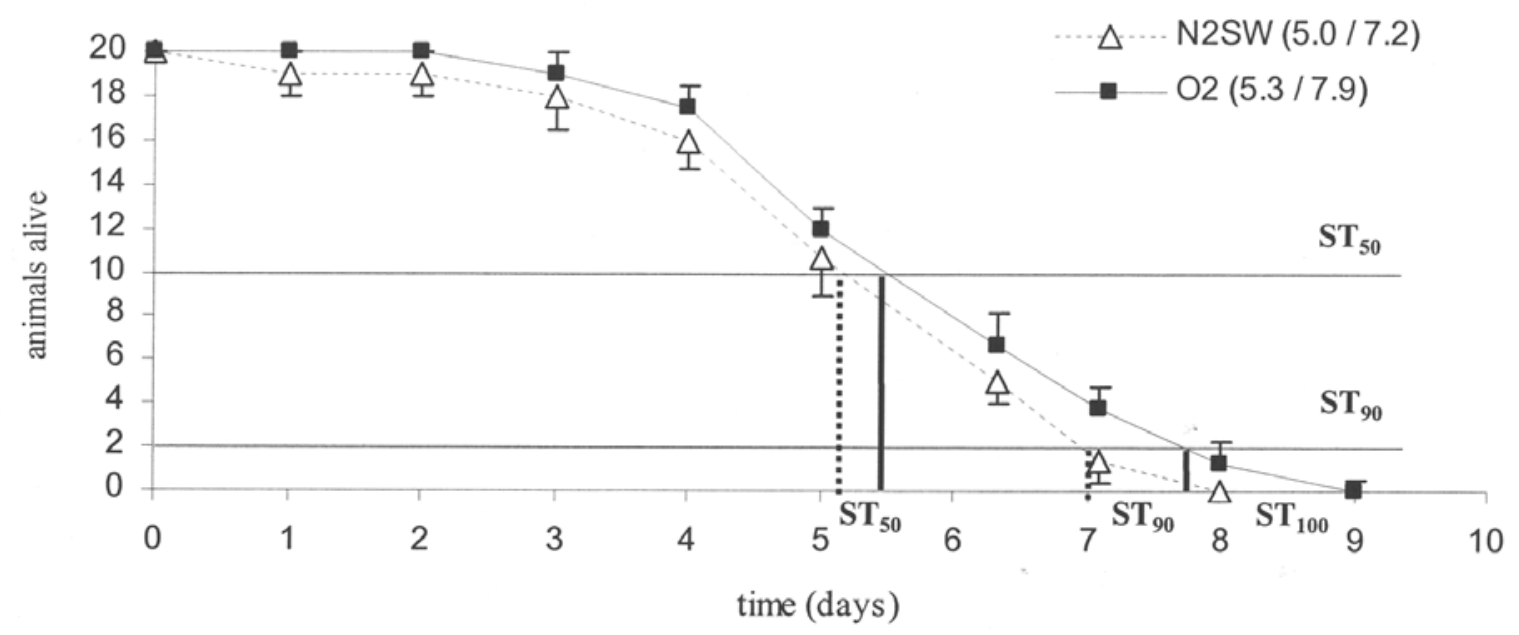

Figure 1. Survival profiles of Mytilus galloprovincialis individuals subjected to air exposure $\left(\mathrm{O}_{2}\right)$ and incubation in anoxic seawater $\left(\mathrm{N}_{2} \mathrm{SW}\right)$ at $22^{\circ} \mathrm{C} . \mathrm{ST}_{50 / 90}$ values are shown in parentheses.

length and tissue dry weight were $50.4 \pm 2.7 \mathrm{~mm}$ and 0.93 $\pm 0.40 \mathrm{~g}$, respectively $(\mathrm{N}=25)$. Condition index values were $4.02 \pm 0.83 \mathrm{mg}$ of soft tissue dry weight per $\mathrm{cm}^{3}$. Individuals were immediately transported to the laboratory, placed in an aquarium with well-aerated running seawater and a mixture of microalgae (Tahitian Isochrysis aff. galbana, TISO) and sediment (40:60 microalgae:sediment, by weight) supplied with a peristaltic pump at constant flow (1.2 mg of particulate matter per litre; $50 \%$ of organic weight). Salinity and temperature were kept at $31 \mathrm{ppt}$ and $22^{\circ} \mathrm{C}$, respectively and individuals were maintained until the experiment was conducted at day five.

\section{Protocol of the experiment}

Two replicates of 20 individuals each were exposed to air in a chamber at $22^{\circ} \mathrm{C}$ on filter paper with continuous humidity for survival measurements. Anoxic seawater was prepared by vigorously bubbling filtered seawater for approximately 2 $\mathrm{h}$ with nitrogen gas in glass reservoirs (oxygen concentration measured lower than $0.15 \mathrm{mg} \mathrm{l}^{-1}$ ). From these reservoirs water was siphoned into 2-1 conical jars while flushing nitrogen gas over the surface. Twenty individuals were introduced in the jars occupying the bottom layer. The flasks were tightly closed with rubber stoppers and only opened shortly once a day to check mortality. Spilled medium as consequence of removing dead animals within the flasks was replaced by freshly prepared anoxic seawater. No food was added during anoxic incubations and incubation media (2-litre) were not exchanged (static systems). Mortality was followed daily. In parallel, a similar number of animals to those used for survival potential (replicates of 20 individuals) were similarly incubated under oxygen-free seawater and emersed on filter paper with the aim of collecting biomass for biochemical determinations after 6, 24 and 48 hours.

\section{Tissue sampling, extraction and analysis of metabolites}

Individuals were sampled and rapidly dissected by excising adductor muscle. Whole soft tissues were collected, placed on a bed of broken ice and squeezed between aluminium blocks that had been pre-cooled in liquid nitrogen. A number of individuals $(\mathrm{N}=3)$ were homogenized as a sample and three samples each with three different individuals were considered. Control individuals were sampled from the aquarium maintained under aerobiosis at 0, 6, 24 and 48 $\mathrm{h}$ of the experimental time. Before preparing the extracts, frozen tissues were lyophilized for $48 \mathrm{~h}$, dry tissues were then powdered, weighted and samples of approximately $100 \mathrm{mg}$ (adenylates and phospho-L-arginine) and $400 \mathrm{mg}$ (anaerobic metabolites) were homogenized in ice cold $7 \%$ perchloric acid (PGA) using an ultra-Turrax $(4 \times 30 \mathrm{~s}$ at maximum speed). The homogenate was centrifuged (30 min, 40000g) and an aliquot of the supernatant was adjusted to $\mathrm{pH} 7-$ 8 with $5 \mathrm{M} \mathrm{K}_{2} \mathrm{CO}_{3}$, and centrifuged again to spin down potassium perchlorate. Adenylate analyses were carried out in a HPLC system equipped with a programmable pump Beckman 126, an ultraviolet-visible detector Beckman 167, a Reodyne injector, reverse phase Kromasil 100 C18 5 $\mu \mathrm{m}$ column $(15 \times 0.4)$ (Teknokroma) and a software system Gold (v. 8.1). For mobile phases used, solutions, flow and detection limits, we refer to Özogul et al. (2000). Nucleotide standards (ATP, ADP and AMP) were purchased from Sigma-Aldrich Chemical Company. Adenylate energy charge (AEG) was established according to Atkinson (1968) and the formula: $\mathrm{EC}=[(\mathrm{ATP}+1 / 2 \mathrm{ADP}) /(\mathrm{ATP}+\mathrm{ADP}+\mathrm{AMP})]$. Phospho-L-arginine (PLA) values were determined spectrophotometrically by using enzymatic tests according to Bergmeyer (1984) and glycogen was quantified as glucose by the phenol-sulphuric acid method (Strickland \& Parsons, 1968) after precipitation with $100 \%$ ethanol.

Anaerobic end products succinate and propionate accumulated in the tissues of $M$. galloprovincialis were determined by HPLG with an ION $300 \times 7.8 \mathrm{~mm}$ column equipped with a pre-column IONGUARD, that permits separation of a mix of sugars, organic acids, alcohols based on its interactions with a cationic exchange column through an isocratic flow of $6 \mathrm{mM} \mathrm{H}_{2} \mathrm{SO}_{4}$ at $0.4 \mathrm{ml} \mathrm{min}^{-1}$, the signals being detected by refractive index. Injection volume was 20 $\mu \mathrm{l}$ and column temperature was maintained at $65^{\circ} \mathrm{C}$. The method produced linear results for the metabolites studied 


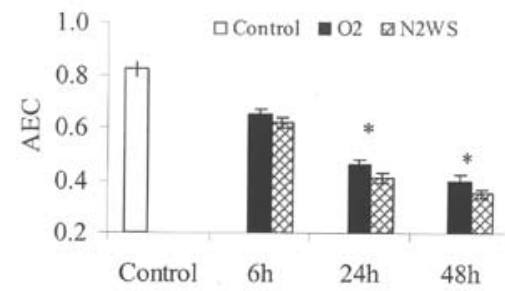

B

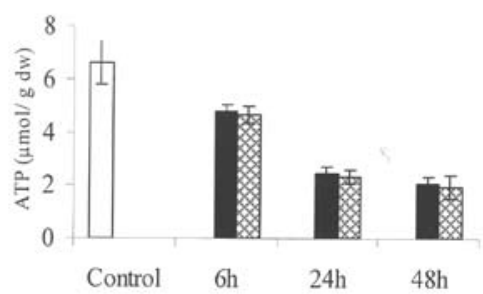

C

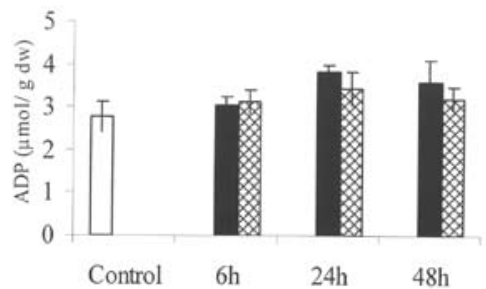

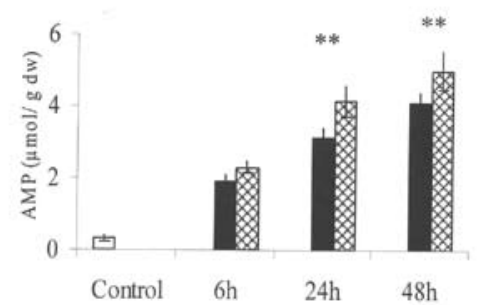

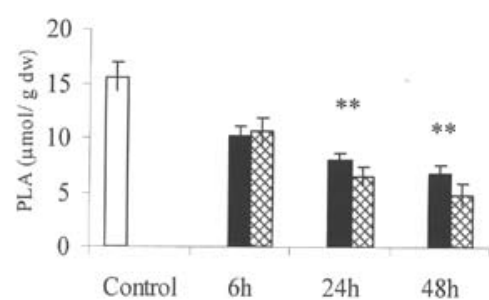

E

Figure 2. (A) Adenylate energy charge (AEG); (B) ATP; (G) ADP; (D) AMP; and (E) phospho-L-arginine (PLA) concentrations as $\mu$ mol per gram of dry weight for the whole tissues of Mytilus galloprovincialis exposed to air $\left(\mathrm{O}_{2}\right)$ and incubated in anoxic seawater $\left(\mathrm{N}_{2} \mathrm{SW}\right)$ for 6 , 24 and $48 \mathrm{~h}$. Control values represented the average values of those individuals kept in aerobiosis during the latter experimental times. Significant differences are shown with asterisks $(* *, P<0.01 ; *, P<0.05)$.

within the concentration range $0.3-12 \mathrm{mmol} \mathrm{l}^{-1}$. Constant additions methodology $\left(4.5 \mathrm{mmol} \mathrm{l}^{-1}\right)$ was used for testing the linearity of the method as well as the responses obtained in different points of this linear profile. Standards were purchased from Fluka Chemie GmbH Buchs.

\section{Statistics}

The non-parametric Kaplan-Meier test was used to estimate log-rank and Wilcoxon values for comparing the survival curves (Kaplan \& Meier, 1958). A confidence limit of $95 \%$ was used to test the significance of differences between groups. $\mathrm{ST}_{50}$ and $\mathrm{ST}_{90}$ values (survival times) were established using the trimmed Spearman-Karber method $(\alpha=10 \%)$ (Hamilton et al., 1997) and Weibull cumulative functions (NIST/SEMATECH e-Handbook of Statistical Methods, http://www.itl.nist.gov/div898/handbook). One-way analysis of variance (ANOVA), two-way ANOVA, Dunnett and $t$ -

Table 1. Two-way ANOVA on logarithmic transformed values of adenylate energy charge (AEC) for soft tissues of Mytilus galloprovincialis as a function of experimental time (6, 24 and $48 \mathrm{~h}$ ) and anaerobic treatment (emersion vs incubation in anoxic seawater).

\begin{tabular}{lcrrrr}
\hline Source & SS & df & MS & F-ratio & $P$ \\
\hline Intercept & 1.7294 & 1 & 1.7294 & 4982.23 & 0.000 \\
Exposure time & 0.4337 & 3 & 0.1446 & 416.49 & 0.000 \\
Treatment & 0.0062 & 1 & 0.0062 & 17.89 & 0.001 \\
Timextreatment & 0.0032 & 3 & 0.0011 & 3.11 & 0.056 \\
Error & 0.0055 & 16 & 0.0003 & & \\
\hline
\end{tabular}

$\mathrm{r}=0.987 ; \mathrm{N}=24 ; \mathrm{df}=16 ; \mathrm{F}=182.4 ; P<0.001$. tests were used to detect the effect of both treatment and experimental time on biochemical components after testing normality of data. Statistica v. 6.0 was used for all these analyses.

\section{RESULTS}

\section{Survival potential}

Survival profiles of Mytilus galloprovincialis subjected to incubation in anoxic seawater and emersion at $22^{\circ} \mathrm{C}$ are shown in Figure 1. The mean survival times as $\mathrm{ST}_{50}$ values were 5.0 and $5.3 \mathrm{~d}$ for individuals incubated in anoxic seawater and emersed individuals, respectively and differences were observed to be residual $(P \approx 0.05)$. However, significant differences were obtained when analysing $\mathrm{ST}_{90}$ (7.2 and $7.9 \mathrm{~d}$, respectively; $P<0.05$ ), as was the case of $\mathrm{ST}_{100}$ values (Figure 1).

\section{Adenylates, energy charge (AEC) and phospho-L-arginine (PLA)}

Figure 2 illustrates changes in adenylate energy charge (AEG), adenylates and phospho-L-arginine (PLA) concentrations in the whole tissues of $M$. galloprovincialis. ATP concentrations did not differ between treatments $(P>0.05)$ but were significantly affected by exposure time $(P<0.01)$. ATP concentrations strongly dropped about $27 \%$ and $63 \%$ after $6 \mathrm{~h}$ and $24 \mathrm{~h}$, respectively from initial aerobic values of 6.51 $\mu \mathrm{mol} \mathrm{g}{ }^{-1} \mathrm{dw}$ (Figure 2B). Decrease in ATP concentrations was accompanied by a slight increase of ADP concentrations but a highly significant increase of AMP concentrations with exposure time $(P<0.01$; Figure $2 \mathrm{C}, \mathrm{D})$. The latter AMP concentrations increase was significantly higher in animals maintained under anoxic incubation (22-34\%) as compared to those emersed after $24-48 \mathrm{~h}(P<0.01$; Figure 2D). In order 
A

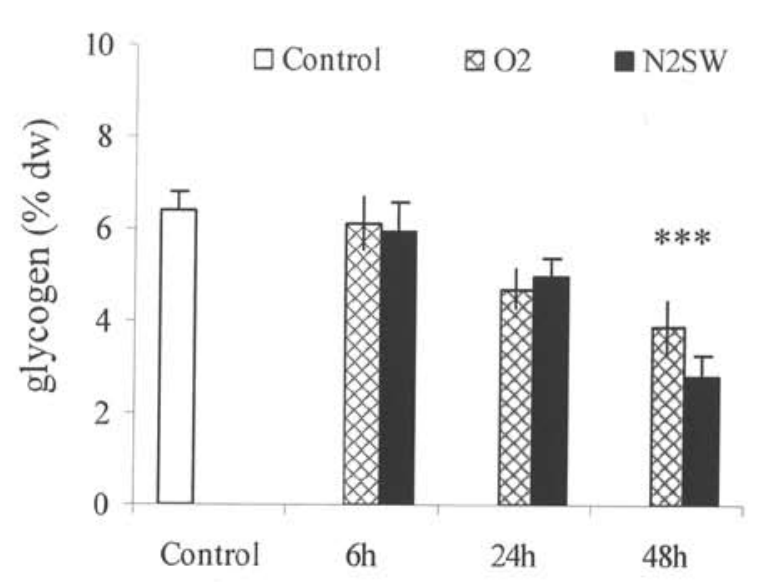

B

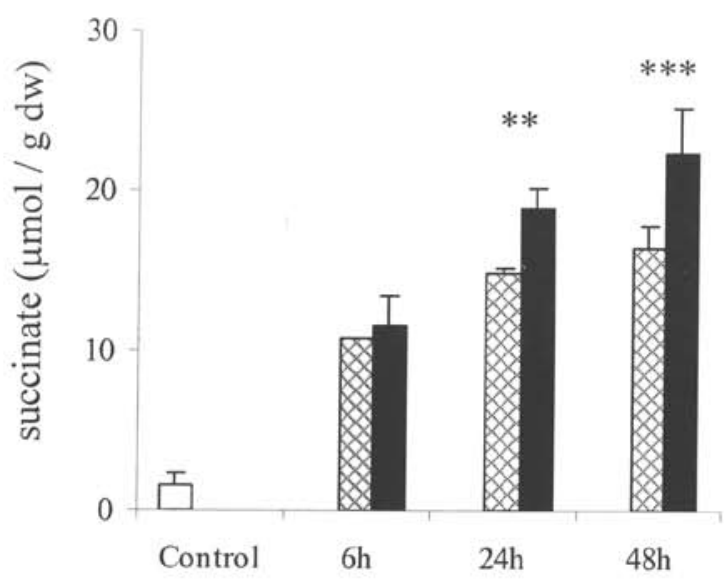

$\mathrm{C}$

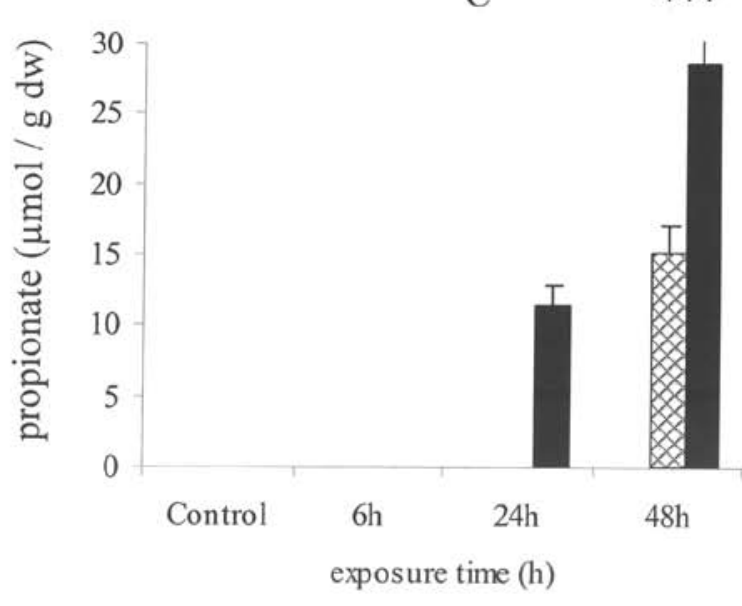

Figure 3. (A) Glycogen content as percentage values of dry weight; (B) succinate; and (C) propionate accumulation as $\mu \mathrm{mol} \mathrm{g}^{-1} \mathrm{dry}$ weight for the whole tissues of Mytilus galloprovincialis exposed to air $\left(\mathrm{O}_{2}\right)$ and incubated in anoxic seawater $\left(\mathrm{N}_{2} \mathrm{SW}\right)$ for 6,24 and $48 \mathrm{~h}$. Control values represented the average values of those individuals kept in aerobiosis during the latter experimental times. Significant differences are shown with asterisks (***, $P<0.001$; **, $P<0.01)$.

to summarize the variability of total amount of adenylates with regard to both sources of variation (experimental time and treatment), two-way ANOVA was performed on integrated AEC values (Table 1). The AEC was significantly affected by both exposure time $(P<0.001)$ and treatment $(P<0.01$; Table 1). AEG values dropped continuously with experimental time but in a higher magnitude under incubation in anoxic seawater than emersion (13\%; Figure 2A). The PLA concentrations showed a significant drop of about 33\% after $6 \mathrm{~h}$ (mean value for both treatments) (Figure $2 \mathrm{E})$. Longer exposure time did cause a further drop of PLA concentrations although at a slower rate, the latter drop being more significant in individuals incubated in anoxic seawater (24-48 h) than under emersion $(P<0.01$; Figure $2 \mathrm{E})$.

\section{Glycogen, succinate and propionate}

Figure 3A-C shows the variability observed for concentrations of glycogen and anaerobic metabolites as succinate and propionate in the whole soft tissues of $M$. galloprovincialis. Glycogen concentrations remained constant after $6 \mathrm{~h}$ in both treatments $(P>0.05)$ but a significant and similar drop in both treatments $(24 \%)$ was observed after $24 \mathrm{~h}(P<0.01)$. Glycogen concentrations dropped more significantly in individuals kept in anoxic seawater (53\%) as compared to those emersed (39\%) after $48 \mathrm{~h}(P<0.001$; Figure $3 \mathrm{~A})$. Succinate concentrations showed a similar 7 fold increase after $6 \mathrm{~h}$ of both treatments (emersion and incubation in anoxic seawater $)(P<0.01)$ and a 10 -fold (emersed) and 13-fold (anoxic seawater) increase after 24 h $(P<0.01$ between treatments). The latter differences in succinate accumulation were maintained after $48 \mathrm{~h}$ up to values of 16.4 (emersion) and 22.4 (anoxic seawater) $\mu \mathrm{mol} \mathrm{g}^{-1}$ $\mathrm{dw}(P<0.001$; Figure 3B). Propionate was not detected after $6 \mathrm{~h}$ of exposure but accumulated up to $11.4 \mu \mathrm{mol} \mathrm{g}{ }^{-1} \mathrm{dw}$ after $24 \mathrm{~h}$ of incubation in anoxic seawater (Figure 3G). After $48 \mathrm{~h}$, propionate concentrations increased by a factor of two with regard to $24 \mathrm{~h}$ for individuals incubated in anoxic seawater and appeared, for the first time, in emersed individuals (15.0 $\mu \mathrm{mol} \mathrm{g}{ }^{-1} \mathrm{dw}$; Figure 3C). 


\section{DISCUSSION}

Mytilus galloprovincialis is able to behave partially aerobic at rates of approximately $6-17 \%$ of aquatic aerobic values when emersed even at a high temperature of $26^{\circ} \mathrm{C}$ (Widdows et al., 1979). Accordingly, a risk of desiccation that could make aerobiosis inappropriate at high temperatures is not likely to occur here with $M$. galloprovincialis maintained at $22^{\circ} \mathrm{C}$. The temperature tested in the present study represents an average summer value at the experimental location and biochemical data evidenced that $M$. galloprovincialis was partially aerobic under emersion (Figures 1-3). First, a lower consumption of the energy reserves as PLA and glycogen was observed in emersed individuals after 24-48 h (Figures $2 \mathrm{E} \& 3 \mathrm{~A}$ ) as compared to mussels kept in anoxic seawater. Second, emersed individuals were also characterized by presenting lower concentrations of succinate and propionate as representative anaerobic end-products (Figure 3B,C) as compared to mussels kept in anoxic seawater. Since aerobiosis would support metabolism with higher efficiency in terms of ATP output (De Zwaan, 1983), better performance might be expected in terms of survival under emersion. The latter relationship was not strongly supported by differences observed in long-term survival profiles measured as $\mathrm{ST}_{50}$ values $(5 \%$ higher values in emersed individuals; $P \approx 0.05)$ but $\mathrm{ST}_{90}-\mathrm{ST}_{100}$ values have to be also considered in order to draw a more complete scheme. Mytilus sp. is characterized by the fact that differences between survival under emersion and anoxic incubation in seawater are of less importance (unpublished results), especially when compared with another well-known gaper species, i.e. Cerastoderma edule (Babarro \& De Zwaan, 2001) that is able to maintain aerobic rates of 28-78\% of aquatic normoxic values (Widdows et al., 1979). However, Mytilus sp. also represents an active gaper that can behave anaerobically and aerobically simultaneously (Shick et al., 1986). Anaerobiosis was similarly activated after $6 \mathrm{~h}$ of emersion and incubation in anoxic seawater according to succinate values (Figure 3B), but the fact that anaerobic substrates (glycogen and PLA) and products (succinate, propionate) followed different patterns after 24$48 \mathrm{~h}$ highlighted a more activated metabolism under anoxia in oxygen-free seawater that might be linked to slight but significant differences in long-term survival capacity as $\mathrm{ST}_{90}$ and $\mathrm{ST}_{100}$ (Figure 1).

An activated anaerobic metabolism under anoxia was also observed for other bivalves such as Mytilus edulis (Zurburg \& Kluytmans, 1980; Zurburg \& Ebberink, 1981) and Scapharca inaequivalvis (Kluytmans et al., 1983), the basis for this physiological change being related to a higher activity of individuals incubated in anoxic seawater that would include valve movements exploring surrounding water (Zurburg \& Ebberink, 1981) and also the possibility that oxygen contributed to some extent in the ATP production under emersion. More recently, factors usually neglected to play a significant role in experimental anaerobiosis, i.e. proliferation of anaerobic bacteria (Babarro \& De Zwaan, 2001) have been reported to interfere with the anaerobic metabolism of individuals and its potential for metabolic arrest (De Zwaan et al., 2002). Indeed, such bacterial proliferation and the concomitant formation of sulphide occurred in our long-term anoxic incubations in seawater (data not shown) and might be responsible for hypothetical differences in long-term metabolic arrest of individuals. Bacterial proliferation in static incubations of Mytilus edulis for nine days at $18^{\circ} \mathrm{C}$ using a similar experimental design to that in the present study was reported to represent values of approximately $12.10^{6}$ bacteria $\mathrm{ml}^{-1}$ and after a lag period of 2-3 d (Babarro \& De Zwaan, 2002).

Differences in biochemical metabolites observed in the present study for the period $24-48 \mathrm{~h}$ cannot be linked, however, with the deterioration of the anoxic (static) system that normally occurs later when mortality begins, but established the basis for a slight but statistically different longterm anaerobic performance of individuals (Figure 1). As a general rule, it has been reported that a lower metabolic rate is related to a higher anoxic survival capacity of individuals (Brooks et al., 1991). More detailed analysis of survival potential is recommended for establishing links between energy metabolism and anaerobic performance especially in species with both aerobic and anaerobic metabolisms operative under stress.

The authors would like to thank F. Martínez and J.L. Garrido for their help in determining adenylates by HPLC, and J.A. Vázquez for anaerobic end-products determination.

\section{REFERENCES}

Atkinson, D.E., 1968. The energy charge of the adenylate pool as a regulatory parameter. Interaction with feedback modifiers. Biochemistry, 7, 4030-4034.

Babarro, J.M.F. \& De Zwaan, A., 2001. Factors involved in the near anoxic survival time of Cerastoderma edule: associated bacteria vs. endogenous fuel. Comparative Biochemistry and Physiology, 128C, 325-337.

Babarro, J.M.F. \& De Zwaan, A., 2002. Influence of abiotic factors on bacterial proliferation and anoxic survival of the sea mussel Mytilus edulis L. Fournal of Experimental Marine Biology and Ecology, 273, 33-49.

Bergmeyer, H.U., 1984. Methods of enzymatic analysis, 3rd edn. Weinheim, Germany: Verlag Chemie.

Brooks, S.P.J., De Zwaan, A., Thillart, G. van den, Cattani, O., Cortesi, P. \& Storey, K.B., 1991. Differential survival of Venus gallina and Scapharca inaequivalvis during anoxic stress: covalent modification of phosphofructokinase and glycogen phosphorylase during anoxia. Fournal of Comparative Physiology, 161B, 207-212.

De Zwaan, A., 1983. Carbohydrate catabolism in bivalves. In The Mollusca, vol 1, (ed. P.V. Hochachka), pp. 137-175. New York: Academic Press.

De Zwaan, A., Babarro, J.M.F., Monari, M. \& Cattani, O., 2002. Anoxic survival potential of bivalves: (arte)facts. Comparative Biochemistry and Physiology, 131A, 615-624.

Eertman, R.H.M., Wagenvoort, A.J., Hummel, H. \& Smaal, A.C., 1993. "Survival in air" of the blue mussel Mytilus edulis L. as a sensitive response to pollution-induced environmental stress. Fournal of Experimental Maine Biology and Ecology, 170, 179-195.

Hamilton, M.A., Russo, R.C. \& Thurston, R.V., 1997. Trimmed Spearmen-Karber method for estimating median lethal concentrations in toxicity bioassays. Environmental Science of Technology, 11, 714-719.

Hochachka, P.W., 1985. Assessing metabolic strategies for surviving $\mathrm{O}_{2}$ lack: role of metabolic arrest coupled with channel arrest. Molecular Physiology, 8, 331-350. 
Isani, G., Cattani, O., Zurzolo, M., Pagnucco, C. \& Cortesi, P., 1995. Energy metabolism of the mussel, Mytilus galloprovincialis, during long-term anoxia. Comparative Biochemistry and Physiology, 110B, 103-113.

Kaplan, E.L. \& Meier, P., 1958. Nonparametric estimation from incomplete observation. Fournal of the American Statistical Association, 53, 457-481.

Kluytmans, J.H., Bont, A.M.T. de, Kruytwagen E.C.J., Ravenstein, H.J.C. \& Veenhof, P.R., 1983. Anaerobic capacities and anaerobic energy production of some Mediterranean bivalves. Comparative Biochemistry and Physiology, 75B, 171-179.

Özogul, F., Taylor, D.A., Quantick, P.C. \& Özogul, Y., 2000. A rapid HPLC-determination of ATP-related compounds and its application to herring stored under modified atmosphere. International Fournal of Food Science and Technology, 35, 549-554.

Shick, J.M., Gnaiger, E., Widdows, J., Bayne B.L. \& De Zwaan, A., 1986. Activity and metabolism in the mussel, Mytilus edulis L. during intertidal hypoxia and aerobic recovery. Physiological Zoology, 59, 627-642.

Shick, J.M., Widdows, J. \& Gnaiger, E., 1988. Calorimetric studies of behaviour, metabolism and energetics of sessile intertidal animals. American Zoology, 28, 161-181.

Sokolova, I.M., Bock, C. \& Pörtner, H.-O., 2000. Resistance to freshwater exposure in White Sea Littorina spp. I. Anaerobic metabolism and energetics. Fournal of Comparative Physiology, 170B, 91-103.

Storey, K.B., Kelly, D.A., Duncan, J.A. \& Storey, J.M., 1990. Anaerobiosis and organ-specific regulation of glycolysis in a marine whelk. Canadian Fournal of Zoology, 68, 974-980.
Strickland, J.D. \& Parsons, T.R., 1968. A practical handbook of sea water analysis. Bulletin of the Fisheries Research Board of Canada, 167, 173-174.

Sukhotin, A.A. \& Pörtner, H.-O., 1999. Habitat as a factor involved in the physiological response to environmental anaerobiosis of White Sea Mytilus edulis. Marine Ecology Progress Series, 184, 149160.

Thomas, R.E., Harris, P. \& Rice S.D., 1999. Survival in air of Mytilus trossulus following longterm chronic exposure to spilled Exxon Valdez crude oil in Prince William Sound. Comparative Biochemistry and Physiology, 122C, 147-152.

Widdows, J., Bayne, B.L., Livingstone, D.R., Newell, R.I.E. \& Donkin, P., 1979. Physiological and biochemical responses of bivalve molluscs to exposure to air. Comparative Biochemistry and Physiology, 62A, 301-308.

Zurburg, W. \& Ebberink, R.H.M., 1981. The anaerobic energy demand of Mytilus edulis organ specific differences in ATPsupplying processes and metabolic routes. Molecular Physiology, 1, 153-164.

Zurburg, W. \& Kluytmans, J.H., 1980. Organ specific changes in energy metabolism due to anaerobiosis in the sea mussel Mytilus edulis (L.). Comparative Biochemistry and Physiology, 67B, 317-322.

Submitted 8 March 2006. Accepted 27 June 2007. 